\title{
Ontogeny of Circadian Rhythms and Synchrony in the Suprachiasmatic Nucleus
}

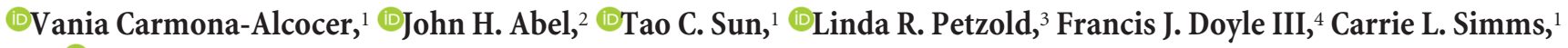 \\ and ${ }^{\circ}$ Erik D. Herzog ${ }^{1}$ \\ ${ }^{1}$ Department of Biology, Washington University in St. Louis, St. Louis, Missouri 63130-4899, 2Department of Systems Biology, Harvard Medical School, \\ Boston, Massachusetts 02115, ${ }^{3}$ Department of Computer Science, University of California, Santa Barbara, Santa Barbara, California 93106, and ${ }^{4}$ John A. \\ Paulson School of Engineering and Applied Sciences, Harvard University, Cambridge, Massachusetts 02138
}

In mammals, the suprachiasmatic nucleus (SCN) of the hypothalamus coordinates daily rhythms including sleep-wake, hormone release, and gene expression. The cells of the SCN must synchronize to each other to drive these circadian rhythms in the rest of the body. The ontogeny of circadian cycling and intercellular coupling in the SCN remains poorly understood. Recent in vitro studies have recorded circadian rhythms from the whole embryonic SCN. Here, we tracked the onset and precision of rhythms in PERIOD2 (PER2), a clock protein, within the SCN isolated from embryonic and postnatal mice of undetermined sex. We found that a few SCN cells developed circadian periodicity in PER2 by $14.5 \mathrm{~d}$ after mating (E14.5) with no evidence for daily cycling on E13.5. On E15.5, the fraction of competent oscillators increased dramatically corresponding with stabilization of their circadian periods. The cells of the SCN harvested at E15.5 expressed sustained, synchronous daily rhythms. By postnatal day 2 (P2), SCN oscillators displayed the daily, dorsal-ventral phase wave in clock gene expression typical of the adult SCN. Strikingly, vasoactive intestinal polypeptide (VIP), a neuropeptide critical for synchrony in the adult SCN, and its receptor, VPAC2R, reached detectable levels after birth and after the onset of circadian synchrony. Antagonists of GABA or VIP signaling or action potentials did not disrupt circadian synchrony in the E15.5 SCN. We conclude that endogenous daily rhythms in the fetal SCN begin with few noisy oscillators on E14.5, followed by widespread oscillations that rapidly synchronize on E15.5 by an unknown mechanism.

Key words: clock genes; ontogeny; VIP

\section{Significance Statement}

We recorded the onset of PER2 circadian oscillations during embryonic development in the mouse SCN. When isolated at E13.5, the anlagen of the SCN expresses high, arrhythmic PER2. In contrast, a few cells show noisy circadian rhythms in the isolated E14.5 SCN and most show reliable, self-sustained, synchronized rhythms in the E15.5 SCN. Strikingly, this synchrony at E15.5 appears before expression of VIP or its receptor and persists in the presence of blockers of VIP, GABA or neuronal firing. Finally, the dorsal-ventral phase wave of PER2 typical of the adult SCN appears $\sim$ P2, indicating that multiple signals may mediate circadian synchrony during the ontogeny of the SCN.

\section{Introduction}

Daily patterns in behavior and physiology are coordinated by circadian pacemakers, which allow organisms to anticipate envi-

Received July 14, 2017; revised 0ct. 7, 2017; accepted 0ct. 17, 2017.

Author contributions: V.C.-A., L.R.P., C.L.S., and E.D.H. designed research; V.C.-A., T.C.S., and C.L.S. performed research; V.C.-A., J.H.A., T.C.S., F.J.D., and E.D.H. analyzed data; V.C.-A., J.H.A., and E.D.H. wrote the paper.

This work was supported by postdoctoral fellowship 237875 Consejo Nacional de Ciencia y Tecnología (CONACYT), the March of Dimes Center for Prematurity, and NINDS Grant 095367. We thank members of the Herzog laboratory for valuable discussions.

The authors declare no competing financial interests.

Correspondence should be addressed to Dr. Erik D. Herzog, Department of Biology, Box 1137, Washington University, St. Louis, M0 63130-4899. E-mail: herzog@wustl.edu.

DOI:10.1523/JNEUROSCI.2006-17.2017

Copyright $\odot 2018$ the authors $\quad 0270-6474 / 18 / 381326-09 \$ 15.00 / 0$ ronmental cycles such as light/dark (Pittendrigh, 1960; Hut and Beersma, 2011). In mammals, the hypothalamic suprachiasmatic nucleus $(\mathrm{SCN})$ is a master circadian pacemaker consisting of $\sim 20,000$ neurons. Individual cells can generate circadian rhythms via a negative feedback loop involving core clock genes including Per2 (Hastings et al., 2014; Takahashi, 2017). How and when these rhythms arise during development is not known.

In mice, SCN neurogenesis occurs between embryonic days $\mathrm{E} 10-\mathrm{E} 15$ (where E1 is the day when a vaginal plug is detectable), peaking between E12-E14 and forming from ventrolateral to dorsomedial (Shimada and Nakamura, 1973; Kabrita and Davis, 2008; Shimogori et al., 2010). Transcription factors such as Lhx1, Shh, Six3, and Six6 participate in the embryonic specifica- 
A
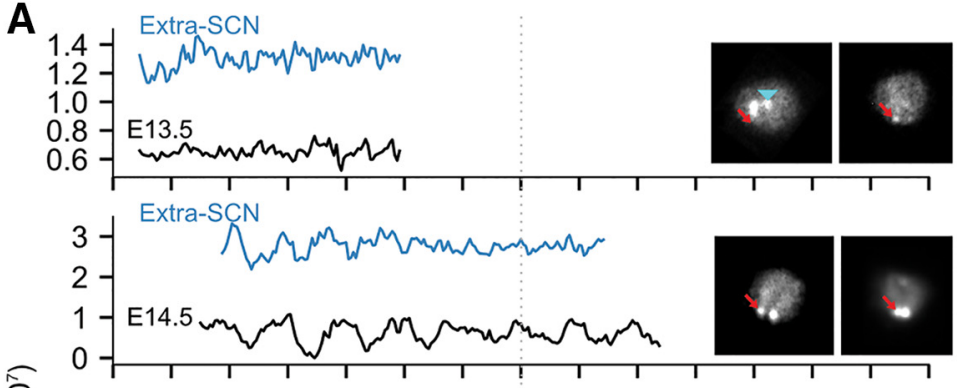

몽
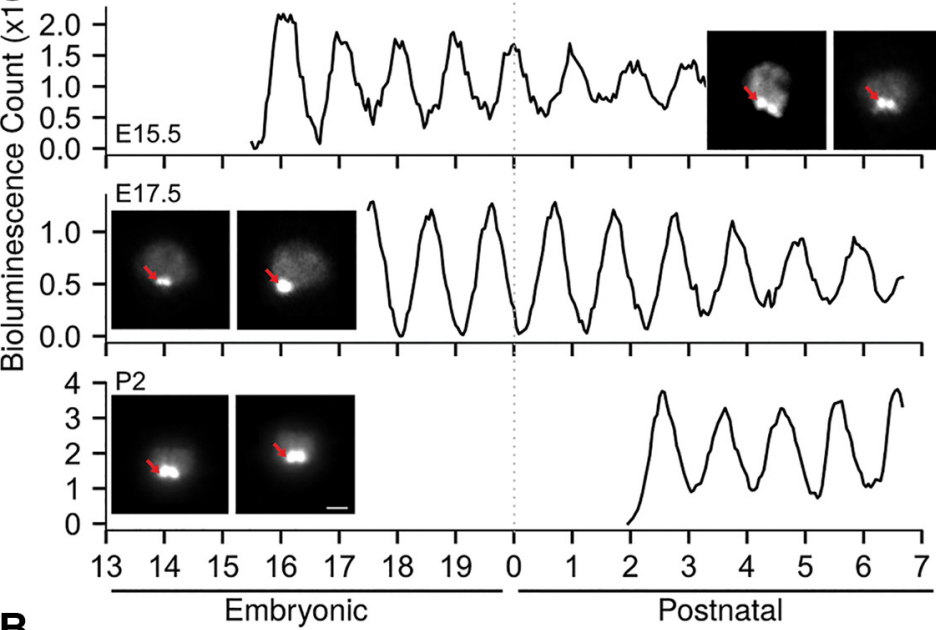

B
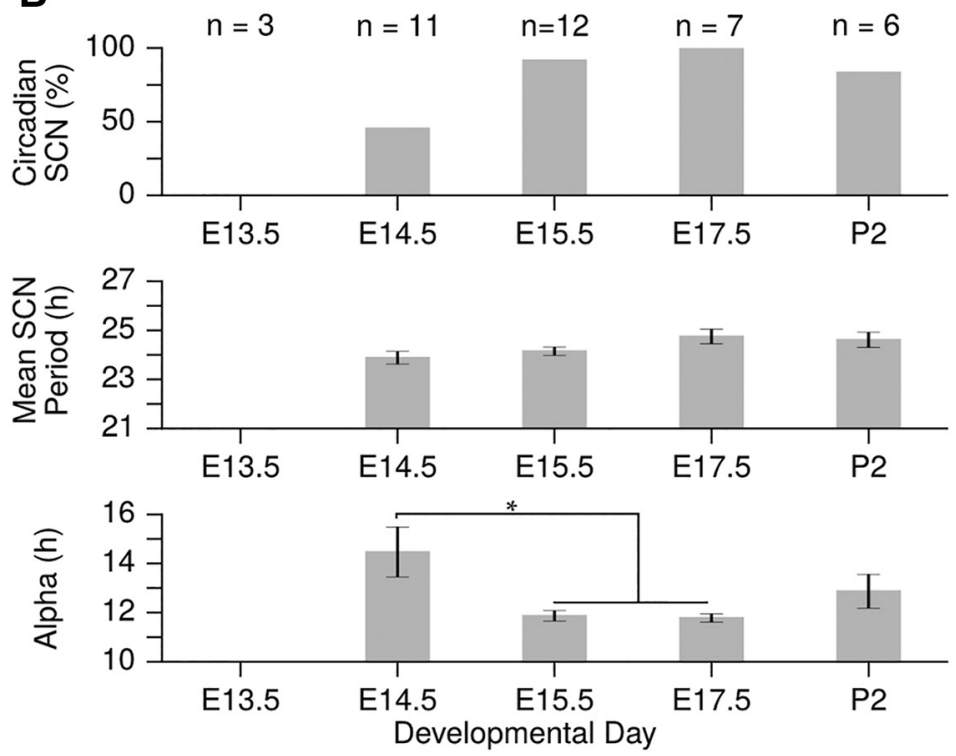

Figure 1. Circadian rhythms in the SCN during development. Long-term, real-time recordings of PER2 expression from SCN harvested after E14.5 showed reliable circadian periods between 18 and $32 \mathrm{~h}$. A, Representative records of $\mathrm{Per} 2^{\text {Luc }}$ bioluminescence from SCN starting on the day they were explanted. Note the weak circadian oscillations that were found in some E14.5 SCN. Insets, Two representative SCN from each age. Some SCN harvested at E13.5 expressed Per2 ${ }^{L u C}$ above the SCN region along the ventricular zone of dorsal hypothalamus (Extra SCN, blue arrowhead; $n=5 / 8$ ). All others harvested at this age and older reliably expressed high levels of PER2 in the bilateral SCN (red arrow). Scale bar: 10 px, $300 \mu \mathrm{m} . \boldsymbol{B}$, Nearly all SCN expressed significant circadian rhythms when harvested on or after E15.5 (top), with periods close to $24 \mathrm{~h}$ (mean $\pm \mathrm{SEM}$; middle) and durations of daily Per2 ${ }^{\text {Luc }}$ expression above the mean close to $12 \mathrm{~h}$ (alpha; mean \pm SEM; bottom; $p<0.05$, one-way ANOVA, Tukey's HSD). Note, eight slices were examined at E13.5, however, we excluded five because they did not express detectable PER2 in the SCN region.

tion of SCN lineages (Shimogori et al., 2010; VanDunk et al., 2011; Clark et al., 2013; Bedont et al., 2014). However, the markers of terminal differentiation and synaptogenesis peak postnatally (Moore and Bernstein, 1989; Shimogori et al., 2010). The rat SCN has fetal day/night differences in 2-deoxyglucose uptake in vivo $\sim \mathrm{E} 19$, in vivo daily oscillations in clock genes including Per2 by E20-E21 and in vitro cycling of electrical activity on the day of birth (E22; Reppert and Schwartz, 1983, 1984; Shibata and Moore, 1987; Sládek et al., 2004; Kováciková et al., 2006; Houdek and Sumová, 2014). The mouse SCN has detectable fetal daily rhythms in Perl transcript levels at E17, and PERIOD1 (PER1) and PER2 proteins by E18 in vivo (Shimomura et al., 2001; Ansari et al., 2009). It is not clear whether these results reflect diurnal rhythms imposed by the mother in utero. Recent studies in vitro have found daily expression of the PER2::LUCIFERASE (Per2 $\left.{ }^{\text {Luc }}\right)$ bioluminescent reporter in the whole $\mathrm{SCN}$ as early as E13 (Landgraf et al., 2015) or E15 (Wreschnig et al., 2014). It is unclear, however, if or when individual cells in the fetal SCN begin to oscillate and to synchronize their daily rhythms to each other.

To drive coherent rhythms in behavior, cells within the SCN must synchronize their genetic oscillations to an identical period and a consistent phase relationship (Mohawk and Takahashi, 2011; Herzog et al., 2015; Evans and Gorman, 2016). Vasoactive intestinal polypeptide (VIP) is required for normal synchrony in the SCN. Daily addition of VIP entrains SCN neurons, and the absence of VIP or its receptor, VPAC2R, reduces synchrony between neurons and consequently eliminates many daily rhythms (Harmar et al., 2002; Colwell et al., 2003; Aton et al., 2005; Maywood et al., 2006; Ciarleglio et al., 2009). It is not known which intercellular signals underlie circadian synchrony during development (Wang et al., 2014; Ono et al., 2016). In this study, we examined the embryonic onset of endogenous $\mathrm{SCN}$ circadian oscillation and intercellular synchrony.

\section{Materials and Methods}

Animals. All mice were maintained on a C57BL/ 6JN background (WT) and housed in a 7:00 A.M. to 7:00 P.M. light/dark cycle in the Danforth Animal Facility at Washington University. The Per2 ${ }^{L u c}$ mouse line was generated by replacing the endogenous mouse Period 2 gene locus with a Per2 ${ }^{L u c}$ reporter construct (Yoo et al., 2004). For immunochemistry, we compared male and female homozygous Per2 $2^{\text {Luc }}$ pups to Vip ${ }^{-1-}$ and Vipr2 $2^{-1-}$ pups as negative controls. Vaginal plugs confirmed overnight mating of each female. We designated the morning after mating as E0.5 and the day of birth as postnatal age 0 . All procedures were approved by the Animal Care and Use Committee of Washington University and followed National Institutes of Health guidelines.

Cultures and bioluminescence recording. Pregnant mice were killed with $\mathrm{CO}_{2}$ and cervical dislocation and their embryos dissected into $4^{\circ} \mathrm{C}$ Hanks buffered saline solution (Sigma-Aldrich). All surgeries started at 1:00 


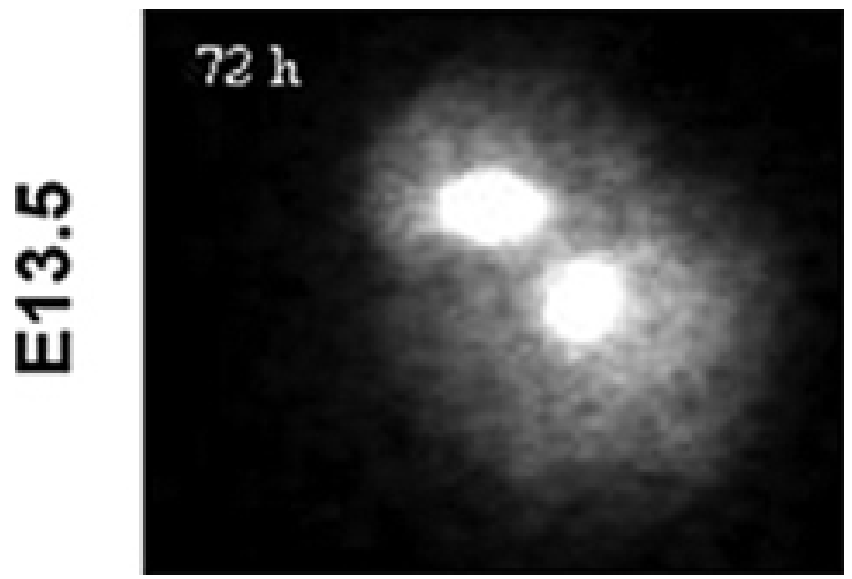

Movie 1. Movie 1. Time-lapse movie of PER2 expression from SCN explanted at E13.5. Note that, at E13.5, the bilateral SCN region had little to no PER2 expression and no circadian rhythms. At this stage, the bilateral ventricular zone of the dorsal hypothalamus had high PER2 levels. PER2 expression increased in the E14.5 SCN, decreased in the dorsal hypothalamus, and showed circadian rhythms when explanted on or after E15.5. A daily dorsal-to-ventral wave of PER2 appeared around P2.

P.M. (Zeitgeber time 06). We recorded bioluminescence from $300 \mu \mathrm{m}$ coronal SCN slices from fetal (E13.5-E15.5 and E17.5) and postnatal day (P)2 homozygous Per2 ${ }^{L u c}$ mice (Landgraf et al., 2015). Briefly, brains were embedded in a block of $4 \%$ low-melting agarose and prepared with a vibraslicer. SCN were dissected with scalpels from sections of the ventral hypothalamus and placed on $0.4 \mathrm{~mm}$ membrane inserts (Millipore) in sealed $35 \mathrm{~mm}$ Petri dishes (BD Biosciences) with $1 \mathrm{ml}$ of DMEM (Sigma-Aldrich, pH 7.2), supplemented with $25 \mathrm{U} / \mathrm{ml}$ penicillin, $25 \mu \mathrm{g} / \mathrm{ml}$ streptomycin (Invitrogen), $10 \mathrm{~mm}$ HEPES (SigmaAldrich), 2\% B27 (Invitrogen), $0.35 \mathrm{~g} / \mathrm{L} \mathrm{NaHCO}_{3}$ (Sigma-Aldrich), and $0.15 \mathrm{~mm}$ beetle luciferin (Promega). SCN explants were transferred to a light-tight incubator at $36^{\circ} \mathrm{C}$ (Onyx, Stanford Photonics). We collected images (XR Mega-10AW camera, Stanford Photonics) every 6 min $(6 \mathrm{~s}$ exposure) and then summed every 10 frames with ImageJ software (http://rsbweb.nih.gov/ij) to provide one image every hour. We applied adjacent frame minimization to each movie to filter out bright noise caused by the camera or cosmic rays.

Data analysis. We analyzed the Per $2^{L u c}$ rhythms of the developing SCN at the level of the whole tissue and with $30 \mu \mathrm{m}$ (pixel) resolution. The statistical analysis for each experiment is described in detail in its respective section. We assessed rhythms measured as the integrated intensity of the SCN tissue with cosinor analysis (software generous gift from B. Meier and A. Kramer, Charité University Berlin). We performed a pixelbased analysis of the same SCN movies. We excluded movies if the corners of the SCN slice moved (3 slices excluded at each of E15.5, E17.5, and P2). We measured periodicity of each pixel $\left(1 \mathrm{px}=900 \mu \mathrm{m}^{2}\right)$ and defined pixels as circadian if they had a dominant period between 18 and $32 \mathrm{~h}$ ( $p<0.05$ by Lomb-Scargle periodogram analysis (Ruf, 1999), or a correlation coefficient $>0.6$ in cosinor analysis. Because the two methods yielded $90 \pm 0.02 \%$ (mean $\pm \mathrm{SE} ; n=30$ brains) agreement in pixel classification, we reported results from the periodogram analysis only. The cycle to cycle variability in Per2 ${ }^{L u c}$ was evaluated by detrending rhythmic cells with a discrete wavelet transform (Leise, 2015) keeping only detail coefficients between 16 and $32 \mathrm{~h}$, and measuring the interpeak distance $(\mathrm{h})$ of each cycle. We evaluated the synchronization index using the Kuramato method (Kuramoto, 2003).

A radial distribution of mean peak times was constructed for each SCN to identify the presence of core-shell structure. The time of the initial peak for each pixel was calculated following detrending. A radial distribution of peak times was constructed by binning individual cell peaks based on radial distance from a reference point in the left core. A null distribution of radial peak times was calculated by bootstrapping: reassigning peak time values at random to pixels within each SCN and recal-

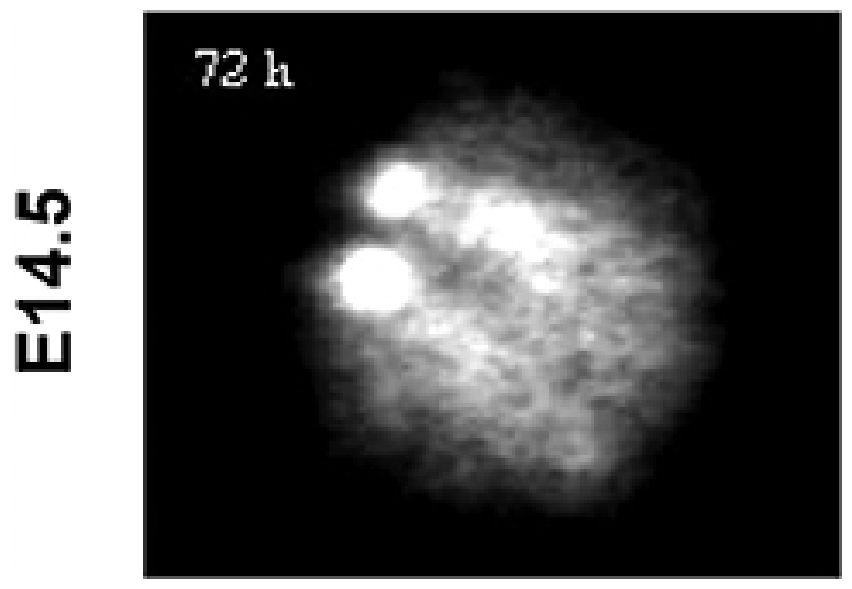

Movie 2. Time-lapse movie of PER2 expression from SCN explanted at E14.5. Note the increased expression in the SCN and decreased expression in the dorsal hypothalamus.
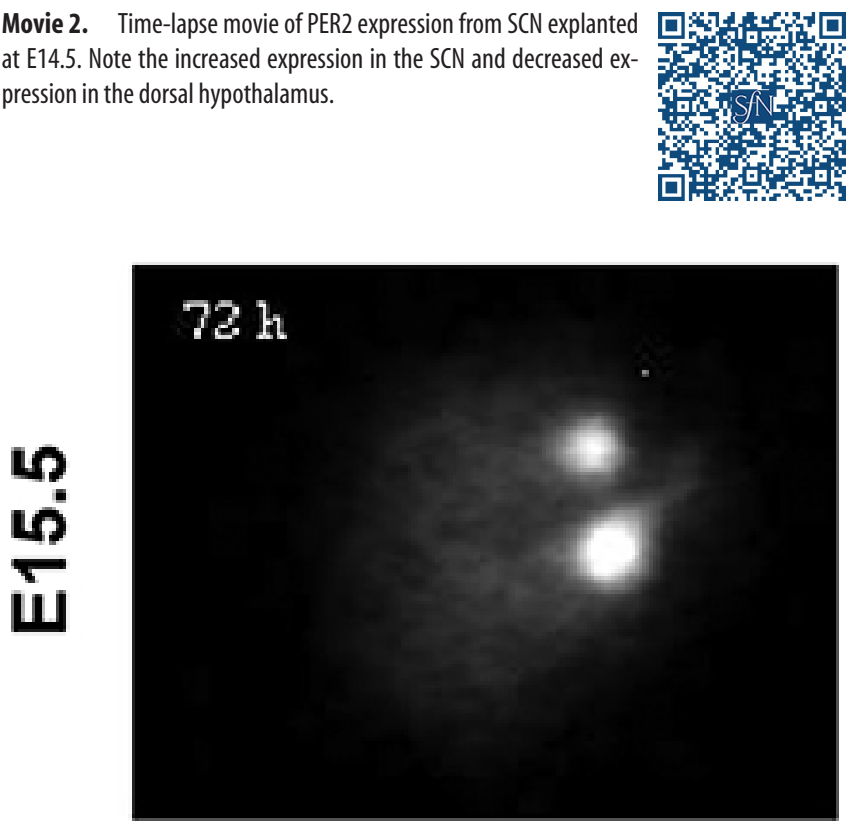

Movie 3. Time-lapse movie of PER2 expression from SCN explanted at E15.5. The bilateral SCN showed circadian rhythms when explanted on or after E15.5.

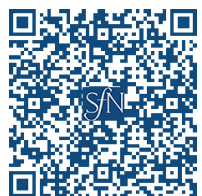

culating the radial distribution using 10,000 bootstrap runs. The SCN was determined to have core-shell structure if the radial peak time distribution showed significant $(p<0.05)$ peaks for the shell region (early peaking, middle distances) and at least one core region (late-peaking, near and far distances).

Software. Data analysis was performed in the Python language, using packages scipy and numpy (Jones et al., 2014), PyWavelets, Statsmodels (Seabold and Perktold, 2010), and Matplotlib (Hunter, 2007). Parallelization of data processing was achieved via iPython (Pérez and Granger, 2007). Code for data processing is available on request.

Immunocytochemistry. Brains of mice from ages E13.5-E17.5, P0, and P2 were removed and fixed in 4\% paraformaldehyde in PBS overnight at $4^{\circ} \mathrm{C}$. We transferred them to $30 \%$ sucrose in PBS for $24 \mathrm{~h}$ at $4^{\circ} \mathrm{C}$ and sectioned in 30- $\mu \mathrm{m}$-thick coronal slices onto microscope slides. The sections were incubated for $1 \mathrm{~h}$ at $4^{\circ} \mathrm{C}$ in a blocking solution $(10 \%$ nonfat dry milk, $10 \%$ bovine serum albumin and $0.3 \%$ Triton $\mathrm{X}-100 \mathrm{in}$ PBS) and then for $48 \mathrm{~h}$ at $4^{\circ} \mathrm{C}$ in an anti-VIP (1:1000; ImmunoStar) or antiVPAC2R (1:1000; Abcam) rabbit polyclonal antibody diluted in 3\% BSA and $0.35 \%$ Triton X-100 in PBS. After washing in PBS, the slides next were incubated at room temperature in a biotinylated goat anti-rabbit 


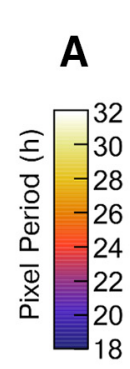

B

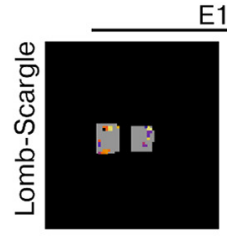

E14.5
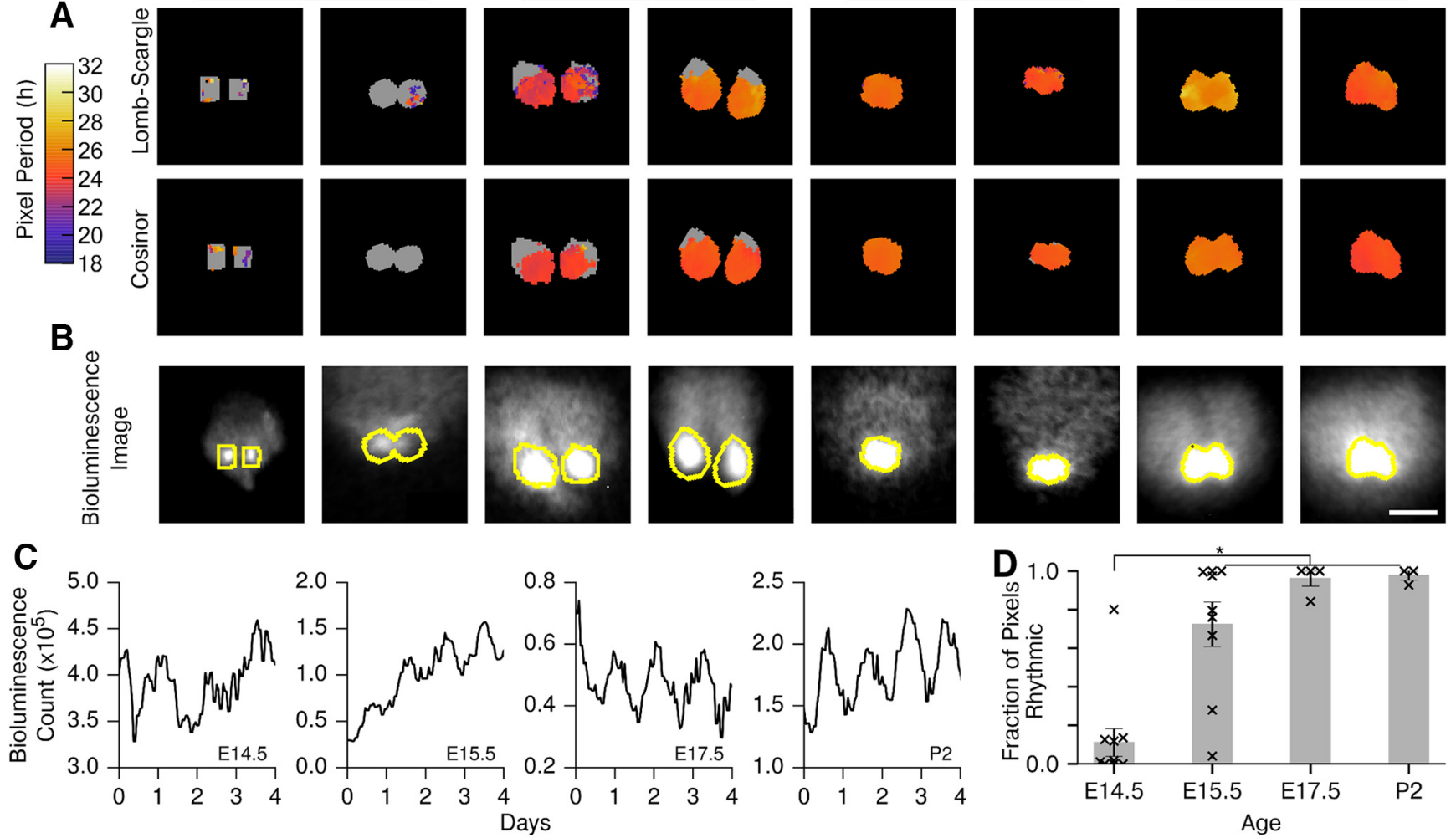

Figure 2. Embryonic SCN cells express PER2 rhythmically beginning $\sim$ E14.5 in vitro. $\boldsymbol{A}$, Heat maps of two SCN explanted at each developmental stage show circadian pixels based on Lomb-Scargle periodogram (power $>p<0.05$ ) and cosinor analysis (correlation coefficient $>0.6$ ). We therefore report results only from periodogram analyses for simplicity. $\boldsymbol{B}$, Representative Per2 2 L bioluminescence images of the same $S C N$ explants (1 h integration, $2 \times 2$ binning). Scale bar: 10 px, $300 \mu \mathrm{m}$. C, Representative Per ${ }^{\text {Luc }}$ bioluminescence recordings from single rhythmic pixels from SCN cultured at different embryonic stages. Note the competence of the E15.5 SCN to generate and sustain circadian rhythms in PER2 protein expression. D, The fraction of circadian pixels in each SCN (mean \pm SEM) was higher for explants at E15.5 and older [ ${ }^{*} p<0.05$, one-way ANOVA, Tukey's HSD; $n=$ at least 3 SCN at each age where age is reported as days post-mating (E0.5) and post-birth (E20.5 = P0)].

A

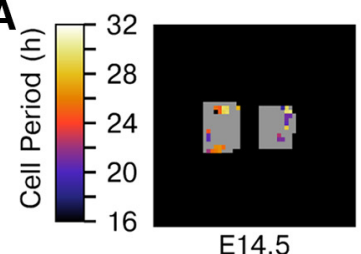

E14.5

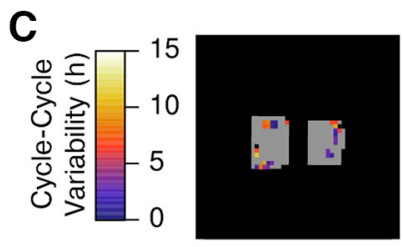

E14.5

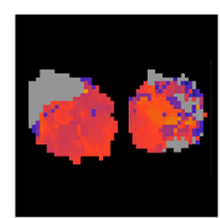

E15.5

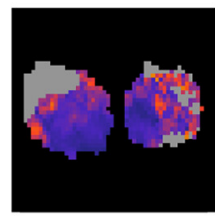

E15.5

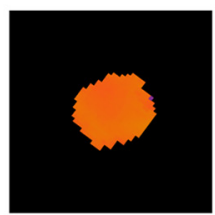

E17.5

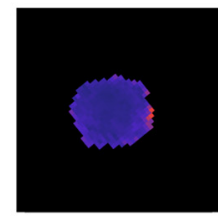

E17.5

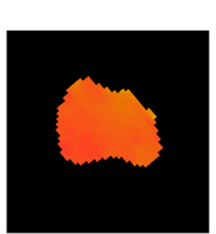

P2

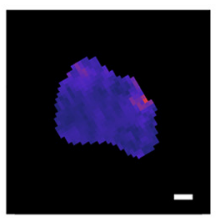

P2
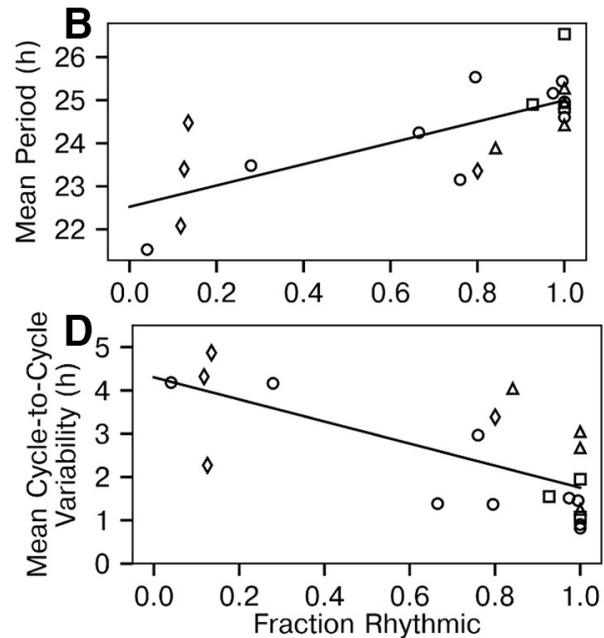

Figure 3. Circadian period and precision of $S C N$ cells increased with development. $\boldsymbol{A}$, Heat maps from representative $S C N$ show the mean period over $5 \mathrm{~d}$ of recording. $\boldsymbol{B}$, The fraction of rhythmic pixels correlated with an increase in the mean SCN period (least-squares linear regression: $p=0.00019$, Pearson's $r=0.74$. SCN with $<5$ circadian pixels were considered arrhythmic and excluded from this analysis; E14.5: diamonds, $n=6$ of 11; E15.5: circles, $n=9$ of 9; E17.5: triangles, $n=4$ of 4; P2: squares, $n=3$ of 3). C, Representative mean cycle-to-cycle variability heat maps show the increase in circadian precision with age. Scale bar, $150 \mu \mathrm{m}$. $\boldsymbol{D}$, The average variability of the daily period across all rhythmic pixels within each isolated SCN inversely correlated with the fraction of circadian cells (least-squares linear regression: $p=0.0006$, Pearson's $r=-0.70$; symbols as in $\boldsymbol{B}$ ), $S C N$ with $<5$ circadian pixels were considered arrhythmic and excluded from this analysis.

$\operatorname{IgG}$ (1:200; Vector Laboratories) for $2 \mathrm{~h}$ and then $\mathrm{ABC}$ solution (1:200; Vectastain Elite ABC Kit, Vector Laboratories) for 2 h. Finally, we incubated each slide in $50 \mathrm{~mm}$ Tris- $\mathrm{HCl}$ using 3,3-diaminobenzidine kit (Sigma-Aldrich). After each step, we rinsed three times for $15 \mathrm{~min}$ in PBS. Mounted sections were dehydrated through a series of ethanol and $x y-$ lene washes. Slides were imaged (NanoZoomer microscope, Leica) and the integrated optical density of the $\mathrm{SCN}$ was measured using ImageJ software (Schneider et al., 2012).

Drug treatments. All drugs were diluted in deionized water and they remained in the recording medium throughout the entire recording 


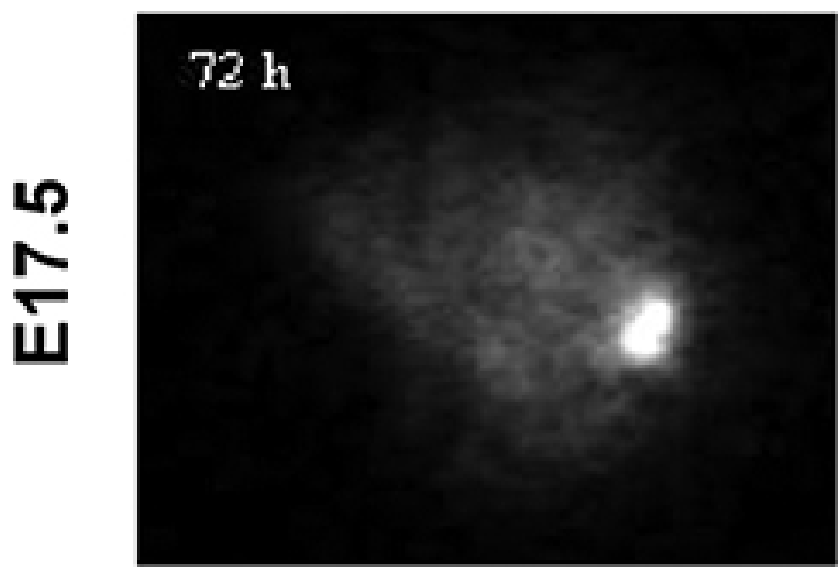

Movie 4. Time-lapse movie of PER2 expression from SCN explanted at E17.5. Note the high amplitude, in-phase circadian rhythms across the SCN.

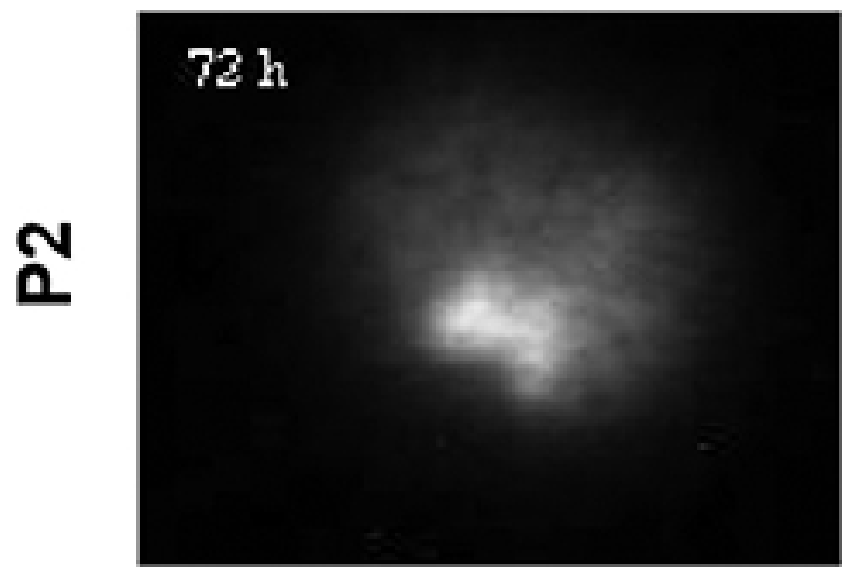

Movie 5. Time-lapse movie of PER2 expression from SCN explanted at P2. Note the appearance of a daily dorsal-to-ventral wave of PER2 across the SCN. without further medium changes. VIP antagonist (200 nм PG-99465) provided by Dr. P. Robberecht (Cutler et al., 2003), GABA antagonist (100 $\mu \mathrm{M}$ Gabazine, Tocris Bioscience), Meclofenamic acid (MEC; $10 \mu \mathrm{M}$; Sigma-Aldrich), or TTX (2.5 $\mu \mathrm{M}$ tetrodotoxin).

\section{Results}

\section{SCN cells become reliable circadian oscillators after E14.5}

Recent in vitro studies have demonstrated the presence of circadian rhythms in PER2 expression in whole SCN explants at E13 (Landgraf et al., 2015) or E15 (Wreschnig et al., 2014), around the times of peak or completed neurogenesis, respectively. To test whether cell-autonomous oscillations appear before tissue-level rhythms, we imaged bioluminescence in fetal Per2 $2^{L u c} / P e r 2^{L u c}$ SCN slices. SCN explanted at E13.5 displayed no tissue-level circadian rhythms ( $n=8$ SCN from 2 litters; Fig. 1). At this stage, the ventricular zone of dorsal hypothalamus expressed high levels of PER2, sometimes in a circadian pattern $(n=2$ of the 8 slices; Movie 1), but the bilateral SCN region had low to no PER2 expression and no circadian rhythms. In contrast, all tissues explanted on E14.5 or later displayed bilateral Per $2^{\text {Luc }}$ expression in the ventral hypothalamus, corresponding to the SCN. By E14.5, $45 \%$ of SCN were circadian (5 of 11 SCN from 4 litters; Fig. 1). Notably, some E14.5 explants ( $n=4$ of 11 ; Movie 2$)$ also displayed no rhythmic Per2 ${ }^{\text {Luc }}$ expression outside the SCN in the ventricular zone of the dorsal hypothalamus. By E15.5, no hypothalamic explants showed high PER2 expression outside the SCN region and nearly all SCN were circadian (Fig. 1; Movie 3; $n=11$ of 12 E15 SCN from 4 litters, 7 of 7 E17 SCN from 2 litters, and 5 of 6 P2 SCN from 1 litter). We conclude that PER2 expression is localized to the SCN and becomes circadian on E14.5.

We next developed methods to culture and image the embryonic SCN for at least $5 \mathrm{~d}$. From these movies, we quantified local circadian rhythms where each pixel included $\sim 10$ or fewer cells (Fig. 2A,B). We found the fraction of circadian pixels (cells) increased approximately sevenfold from E14.5 (Fig. 2C,D; $0.10 \pm$ 0.07 , mean \pm SEM; $n=11$ SCN from 4 litters) to E15.5 [0.72 \pm $0.11 ; n=9$ SCN from 4 litters; ${ }^{\star} p<0.05$, one-way KruskalWallis $\mathrm{H}(3)=10.62$, with post hoc Tukey's Honestly Significant Difference (HSD)]. Nearly all regions were circadian in SCN explanted on E17.5 $(0.96 \pm 0.03 ; n=4$ SCN from 2 litters $)$ and postnatal day $2(\mathrm{P} 2,0.97 \pm 0.02 ; n=3 \mathrm{SCN}$ from 1 litter $)$. The developmental increase in the number of circadian regions correlated with an increase in circadian period in the SCN (Fig. $3 A, B)$. We conclude that a small number of SCN cells initiate endogenous circadian rhythmicity by E14.5, and by E15.5 SCN cells are rhythmic throughout the SCN.

To determine the precision of SCN rhythms during development, we measured the cycle-to-cycle difference in period for each pixel within the fetal SCN over $3 \mathrm{~d}$ of the recording. Interestingly the increase in the number of circadian oscillators correlated with an increase in circadian precision (Fig. $3 C, D)$, suggesting that addition of circadian cells lengthens and stabilizes period in the SCN.

\section{The phase wave typical of adult SCN appears $\sim \mathrm{P} 2$}

In adults, PER2 expression progresses as a daily wave from dorsal to ventral across the SCN (Yan and Okamura, 2002; Quintero et al., 2003; Yamaguchi et al., 2003; Evans et al., 2011). We examined when this spatiotemporal patterning of circadian expression arises in the SCN. To do so, we identified the times of daily peak PER2 in each pixel of the SCN and tested for spatial organization of expression. We found reliable daily waves of PER2 from the dorsal to ventral SCN by P2, but not at earlier developmental stages (Movies 4, 5; Fig. 4). We conclude that phase relationships among SCN cells continue to mature after birth.

\section{Onset of synchrony and intercellular communication within the SCN}

Synchronous circadian oscillations in the SCN are required to coordinate daily rhythms in behavior (Schwartz et al., 1987; Aton et al., 2005; Ohta et al., 2005). To test how synchrony develops, we measured the cycle-to-cycle variability in period length and the synchrony index (SI), a quantity that ranges from 1.0 (all oscillators peak together) to 0.0 (all cells peak at uniformly different times of day) from $5 \mathrm{~d}$ of recording. We found that synchrony tends to increase between E14.5 (Fig. 5; SI $=0.80 \pm$ $0.5, n=6 \mathrm{SCN})$ and E15.5 $(\mathrm{SI}=0.87 \pm 0.05, n=9 \mathrm{SCN})$ reaching a maximum $\sim \mathrm{E} 17.5(\mathrm{SI}=0.91 \pm 0.02, n=4)$ and $\mathrm{P} 2$ (SI $=0.94 \pm 0.02, n=3 \mathrm{SCN} ; 1$ unilateral due to changes during recording between halves). Although there is no significant differences in the SI between ages, SI was positively correlated with the 
A
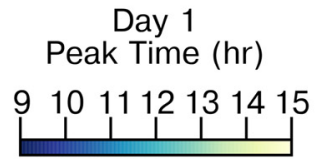

E14.5

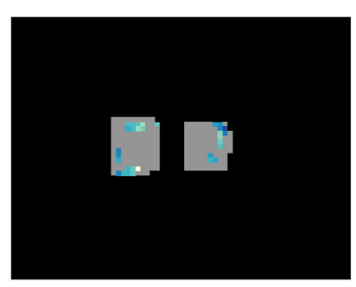

E15.5

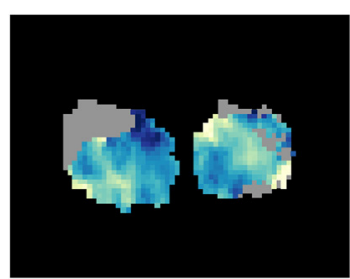

E17.5
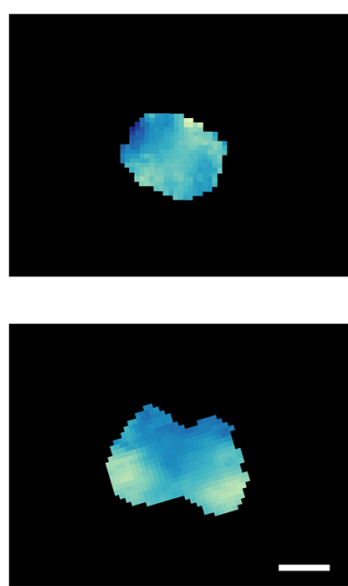

B Radial Peak Time Distribution

- Mean Peaks . . Cell Peaks

Null Distribution, $95 \% \mathrm{Cl}$
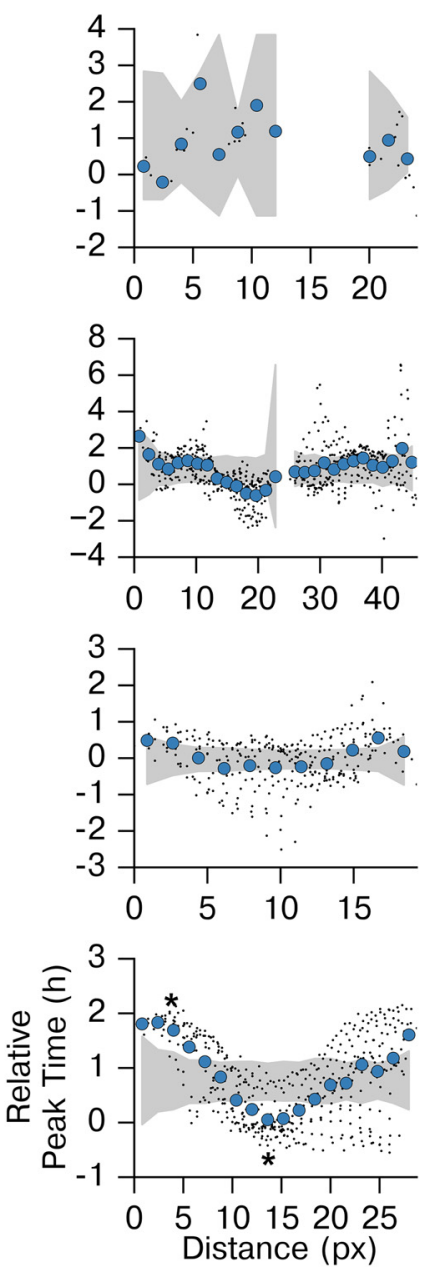

Figure 4. The phase wave of PER2 expression in the SCN appeared only after birth. $\boldsymbol{A}$, Heat maps of the time of peak PER2 expression across representative SCN. Note the dorsal-to-ventral distribution across the cells of the P2 SCN. Scale bar, $300 \mu \mathrm{m}$. $\boldsymbol{B}$, Radial distribution of peak times revealed a core-shell structure in the $\mathrm{P} 2$, but not younger SCN explants. We compared the average differences in the times of peak PER2 expression as a function of distance from the ventral margin of each $\mathrm{SCN}$ with a null distribution of randomly shuffled peak times (shaded area $=95 \%$ Cl for mean peak time calculated from 10,000 resamples). At P2, PER2 peaked significantly later in the ventral core than the dorsal shell, as seen in this representative example.

fraction of SCN cells displaying daily rhythms, indicating that intercellular synchrony is developed simultaneously with increased endogenously generated cellular oscillation (Fig. 5C).

We next examined the signaling pathways that could enable synchronization of SCN cells starting $\sim$ E15.5. VIP signaling is necessary for coordinated circadian rhythms among SCN cells and in behavior of adult mice (Harmar et al., 2002; Colwell et al., 2003; Aton et al., 2005; Maywood et al., 2006; Ciarleglio et al., 2009). We measured the levels of VIP, and its cognate receptor, VPAC2R, by immunocytochemistry between days E14.5 and P2 (Fig. 6). We found VIP $(12.5 \pm 2.3, n=7)$ and VPAC2R [15.0 \pm 5.6 relative optical density (ROD), $n=6$ ] were detectable postnatally above baseline (immunolabeling in the P2 SCN of $V_{i p}{ }^{-1-}=$ $2.1 \pm 0.7$ ROD, $n=5$ brains; Vipr $2^{-/-}=3.8 \pm 2.1$ ROD, $n=5$, mean \pm SEM), but not earlier stages. To further explore this surprising result, we found that a VIP antagonist did not affect synchrony of the E15.5 SCN (Fig. 7). Consistent with prior publications, we found that addition of the VPAC2R antagonist reduced the fraction of circadian cells in the isolated adult SCN to $30 \%$ from $84 \%$ ( $n=1$ adult SCN; Cutler et al., 2003; Aton et al., 2005). We conclude that VIP and its receptor VPAC2R appear in the SCN after the initiation of circadian rhythms and are not required for circadian synchrony among embryonic SCN cells.

We then performed further pharmacological experiments to test whether GABA and/or gap junctions, other candidate coupling mechanisms, might drive synchrony in the SCN before VIP expression begins. Remarkably, antagonists against either or both GABA and gap junctions did not reduce the synchrony index of the E15.5 SCN (Fig. 7).

\section{Discussion}

Our results indicate that E15.5 is a critical time in the maturation of the SCN. Realtime imaging revealed that the clock gene, PER2, appears on E14.5 in the SCN and $\sim 10 \%$ of SCN cells are weakly circadian. By E15.5, nearly all cells within the SCN develop precise circadian rhythms. The cells of the E15.5 SCN are thus competent circadian oscillators. Previous work related this age with the end of neurogenesis (Shimada and Nakamura, 1973; Kabrita and Davis, 2008; Shimogori et al., 2010). At this age the expression of transcription factors as Lhx 1 and ROR $\alpha$ have a wider distribution across the SCN (VanDunk et al., 2011). Interestingly, $\operatorname{ROR} \alpha$ is a positive regulator of Bmal1 expression (Sato et al., 2004), Bmal1 is an essential transcription factor in circadian rhythmogenesis and activator of $\mathrm{Per}$ gene expression (Hastings et al., 2014; Takahashi, 2017). In adults, $\operatorname{ROR} \alpha$ knock-outs showed slight behavioral abnormalities in circadian rhythms. We therefore hypothesize that cell autonomous expression of $\operatorname{ROR} \alpha$ or another factor at E15.5 induces the onset of widespread, sustained circadian oscillations in SCN cells.

Studies using stem cells showed gradual development of circadian oscillations after inducing differentiation with retinoic acid (Yagita et al., 2010; Inada et al., 2014), suggesting that circadian rhythms can be initiated without direct maternal input early during differentiation. Consistent with a prior publication (Landgraf et al., 2015), we found little to no evidence that SCN cells become circadian spontaneously in vitro. For example, SCN explanted on 13.5 were arrhythmic and did not show an increase in the fraction of rhythmic pixels over the course of the experiment. SCN isolated at E14.5 or E15.5 similarly did not show changes in the amplitude, period, variability, or fraction of circadian cells during $7 \mathrm{~d}$ of recording. Although we cannot rule out that arrhythmic, fetal SCN cells cultured $>7 \mathrm{~d}$ might develop daily cycling, our results indicate that the transition from arrhythmic to circadian is rapid and likely requires signals from outside the fetal SCN. 

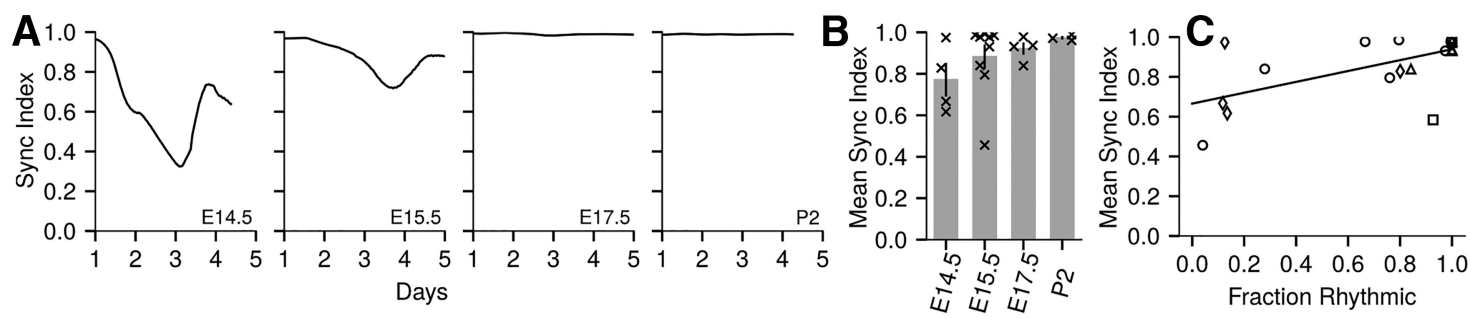

Figure 5. The synchrony between $\mathrm{SCN}$ cells increased and became more stable as the fraction of circadian cells increased. $A$, Representative traces of the synchronization index (also called the Kuramato order parameter or Rayleigh statistic, $r$ ) among regions within the cultured SCN at different ages. $\boldsymbol{B}$, The average synchronization index of SCN slices (mean $\pm S E M ; 24 \mathrm{~h}$ excluded from either end of analysis) did not reliably increase with age, but $(\boldsymbol{C})$ correlated with the fraction of circadian cells in the SCN (symbols as in Fig. 3; least-squares linear regression: $p=0.004$, Pearson's $r=0.61, n=$ at least $3 \mathrm{SCN}$ at each age).

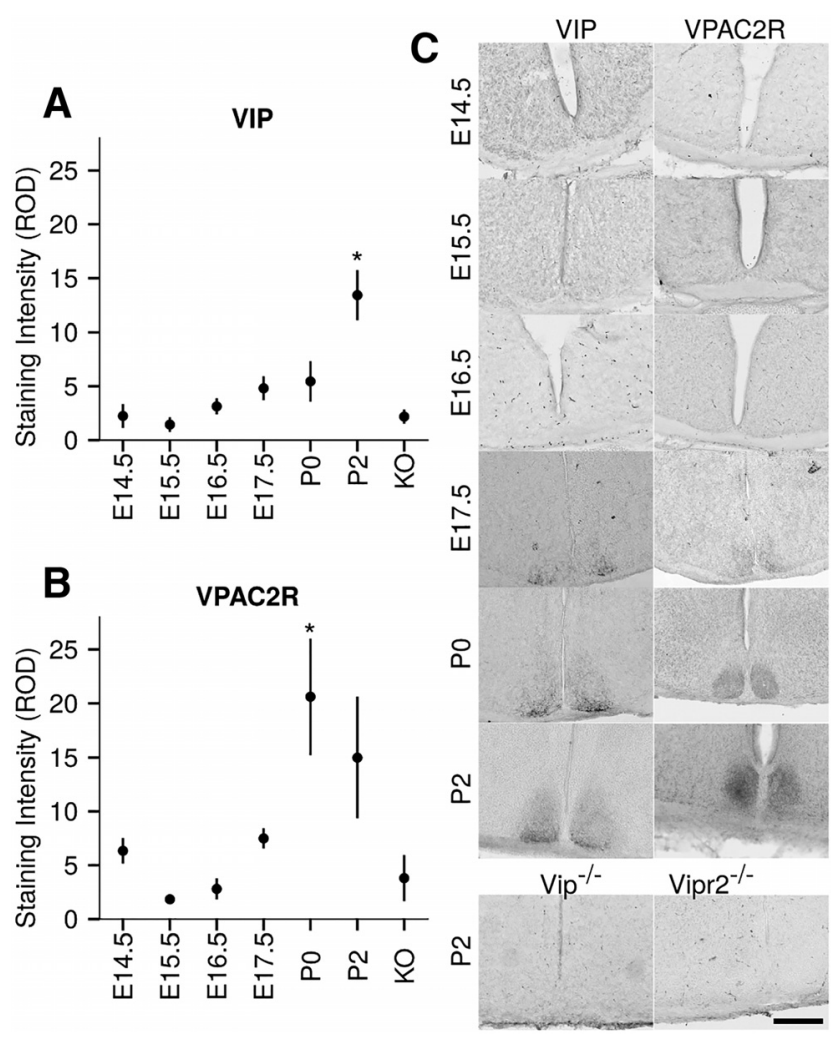

Figure 6. VIP and VPAC2R expression matured in the postnatal SCN. $\boldsymbol{A}$, Immunostaining intensity (mean relative optical density $\pm \mathrm{SEM} ; n=9,5,7,6,7$ and 7 brains at each age, respectively) of VIP in the SCN was significant by $\mathrm{P} 2$ compared with Vip knock-out controls ( $n=5$; ${ }^{*} p<0.05$, one-way ANOVA with Tukey's HSD). $\boldsymbol{B}$, Immunostaining intensity (mean \pm SEM) of $\operatorname{VPAC2R}(n=6,6,5,5,7$, and 6 brains, respectively) was significant by P0 compared with Vipr2 knock-out controls ( $n=5$; ${ }^{*} p<0.05$, one-way ANOVA with Tukey's HSD). C, Representative coronal SCN sections show the VIP (left) and VPAC2R (right) immunoreactivity at different ages. Scale bar, $200 \mu \mathrm{m}$.

We found no circadian rhythms at E13.5, a small fraction of cells expressed noisy circadian rhythms at E14.5 and nearly all cells were circadian by E15.5. Notably, we found that PER2 was first expressed outside the SCN. At E14.5, extra-SCN PER2 expression was high and occasionally circadian. This extra-SCN expression diminishes by E15.5. It is not clear whether these cells move into the SCN or remain in the dorsal hypothalamus while reducing their PER2 expression. Inclusion of these extra-SCN regions in explants could explain the discrepancy between the two studies that reported the onset of PER2 daily oscillations in hypothalamic explants at E13 or E15 (Wreschnig et al., 2014; Landgraf et al., 2015). Importantly, the correlations in the in- creasing fraction of rhythmic cells, increasing circadian period and increasing intercellular and intracellular period precision during this time could reflect the consequences of cell-cell communication (Webb et al., 2009) and/or maturation of molecular components for circadian rhythm generation (VanDunk et al., 2011; Ono et al., 2016). Previous studies demonstrated that embryonic SCN have a strong phase-setting in response to perturbations such as surgical isolation (Wreschnig et al., 2014; Landgraf et al., 2015). Together, these data suggest that SCN cells become intrinsically circadian between E14.5 and E15.5. The presence of a functional circadian clock early in development may indicate the importance of precisely coordinating processes in the fetus such as cell division and differentiation, which are adversely affected in Clock mutant mice (Du Pré et al., 2014; Inada et al., 2014; Kobayashi et al., 2015).

The SCN in adult mice displays a dorsal to ventral phase wave in clock gene expression (Yan and Okamura, 2002; Quintero et al., 2003; Yamaguchi et al., 2003; Evans et al., 2011). Because this phase wave is not a fixed property (e.g., can adopt a different pattern after a temperature manipulation in vitro (Jeong et al., 2016), it is important to consider whether the results from the isolated SCN reflect its in vivo circadian properties. Critically, our results indicate that under constant conditions, the SCN phase wave first appears after birth. Because we isolated SCN at the same time of day, regardless of developmental age, we conclude that, although surgery can alter circadian phase (Wreschnig et al., 2014; Landgraf et al., 2015), it is unlikely to initiate rhythms in the fetal SCN or the spatial wave seen in the more mature SCN. This postnatal maturation of this SCN network likely involves synaptogenesis which begins $\sim \mathrm{P} 2$ when we found the onset of the phase wave (Bedont and Blackshaw, 2015). It will be intriguing to map the synaptic network topology that contributes to the phase relationships among SCN cells (Abel et al., 2016; Buijink et al., 2016).

Though the network continues to mature after birth, we found that intercellular synchrony is achieved much earlier. A prior report found that surgery can reset rhythms in the fetal SCN (Landgraf et al., 2015). Here, we found that synchrony of E14.5 and immature E15.5 SCN decreased over the recording, indicating weak or no synchronization between cells. Previous studies also relate an increase in the period variability with a loss of synchrony between cells (Honma et al., 2004; Webb et al., 2009). Our data showed an increase in synchrony by E15.5 (Fig. 5) corresponding to a decrease in cycle-to-cycle period variability, supporting this hypothesis. In adults, VIP and its receptor VPAC2R play a critical role in synchronizing oscillators in the SCN (Harmar et al., 2002; Colwell et al., 2003; Aton et al., 2005; Maywood et al., 2006; Ciarleglio et al., 2009). Although the expression of VIP mRNAs has been detected at E18 in rat (Ban et al., 1997; Houdek and Sumová, 2014) and VIP protein expression has been studied dur- 


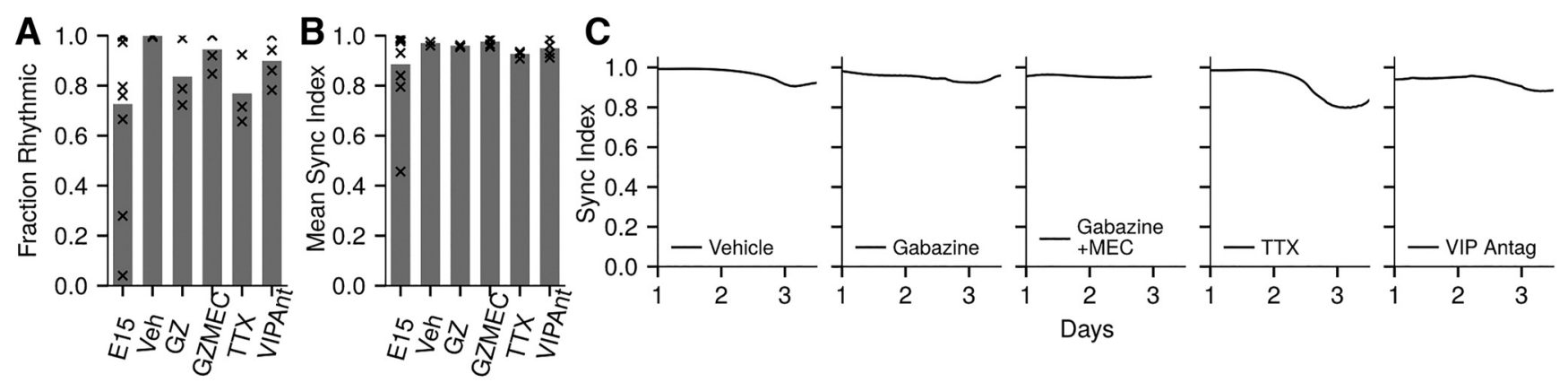

Figure 7. Antagonists of GABA or VIP signaling, gap junctions or neuronal firing did not disrupt circadian synchrony in the developing SCN. Drugs applied during the first day of culture of E15.5 SCN explants did not change $(\boldsymbol{A})$ the fraction of pixels with circadian Per2 ${ }^{\text {Luc }}$ (gray bars show the means across all SCN recorded at each developmental stage), or (B) the mean sync index over the $5 \mathrm{~d}$ of recording. C, The synchronization index within a representative cultured E15.5 SCN treated with Veh (Vehicle), Gabazine (Gz; $100 \mu \mathrm{M}), \mathrm{MEC}(10 \mu \mathrm{M}), \mathrm{VIP}$ antagonist (200 nM; PG-99465), or TTX (2.5 $\mu \mathrm{M})$.

ing postnatal ages (Herzog et al., 2000), our results show that the protein is not detectable by immunochemistry before birth. Interestingly, embryonic SCN explants from mice lacking VIP maintain circadian oscillations at the tissue level (Wreschnig et al., 2014). Moreover, our results demonstrate that synchrony occurs at E15.5, before the expression of VIP or receptor VPAC2R. That the exogenous application of VIP antagonist does not decrease synchrony suggests that other signals are likely involved in sustaining synchrony before the presence of VIP. There is evidence that dopamine, melatonin, or rhythmic feeding may be involved in establishing synchrony between the mother and fetal SCN to coordinate rhythmic cellular processes (Davis and Mannion, 1988; Weaver and Reppert, 1989; Viswanathan et al., 1994). The dopamine pathway in particular merits further investigation as a potential mechanism driving synchrony in the fetal SCN.

The increase in synchrony in the SCN at E15.5 does coincide with Lhx1 expression across the SCN (VanDunk et al., 2011). This transcription factor is important for the expression of diverse neuropeptide coupling signals aside from VIP, such as GRP or AVP (Bedont et al., 2014). Because these signals can mediate the synchrony in adults (Brown et al., 2005; Maywood et al., 2011) and in postnatal ages (Ono et al., 2016), they are candidates for mediating SCN synchrony in embryonic development. In rats the first synapses appear in perinatal ages and the sharp increase between P4 and P10 (Moore and Bernstein, 1989) suggests that other mechanisms could mediate synchrony before synapse formation. Gap junctions have recently been shown to not contribute to circadian synchrony in the adult SCN (Diemer et al., 2017). Our results, with a blocker of gap junctions, further indicate that they do not play a role in establishing synchrony during SCN development. We conclude that cellular circadian oscillations occur simultaneously with the onset of synchrony by unknown mechanisms.

\section{References}

Abel JH, Meeker K, Granados-Fuentes D, St John PC, Wang TJ, Bales BB, Doyle FJ 3rd, Herzog ED, Petzold LR (2016) Functional network inference of the suprachiasmatic nucleus. Proc Natl Acad Sci U S A 113:45124517. CrossRef Medline

Ansari N, Agathagelidis M, Lee C, Korf HW, von Gall C (2009) Differential maturation of circadian rhythms in clock gene proteins in the suprachiasmatic nucleus and the pars tuberalis during mouse ontogeny. Eur J Neurosci 29:477-489. CrossRef Medline

Aton SJ, Colwell CS, Harmar AJ, Waschek J, Herzog ED (2005) Vasoactive intestinal polypeptide mediates circadian rhythmicity and synchrony in mammalian clock neurons. Nat Neurosci 8:476-483. CrossRef Medline

Ban Y, Shigeyoshi Y, Okamura H (1997) Development of vasoactive intestinal peptide mRNA rhythm in the rat suprachiasmatic nucleus. J Neurosci 17:3920-3931. Medline
Bedont JL, Blackshaw S (2015) Constructing the suprachiasmatic nucleus: a watchmaker's perspective on the central clockworks. Front Syst Neurosci 9:74. CrossRef Medline

Bedont JL, LeGates TA, Slat EA, Byerly MS, Wang H, Hu J, Rupp AC, Qian J, Wong GW, Herzog ED, Hattar S, Blackshaw S (2014) Lhxl controls terminal differentiation and circadian function of the suprachiasmatic nucleus. Cell Rep 7:609-622. CrossRef Medline

Brown TM, Hughes AT, Piggins HD (2005) Gastrin-releasing peptide promotes suprachiasmatic nuclei cellular rhythmicity in the absence of vasoactive intestinal polypeptide VPAC2 receptor signaling. J Neurosci 25: 11155-11164. CrossRef Medline

Buijink MR, Almog A, Wit CB, Roethler O, Olde Engberink AH, Meijer JH, Garlaschelli D, Rohling JH, Michel S (2016) Evidence for weakened intercellular coupling in the mammalian circadian clock under long photoperiod. PloS One 11:e0168954. CrossRef Medline

Ciarleglio CM, Gamble KL, Axley JC, Strauss BR, Cohen JY, Colwell CS, McMahon DG (2009) Population encoding by circadian clock neurons organizes circadian behavior. J Neurosci 29:1670-1676. CrossRef Medline

Clark DD, Gorman MR, Hatori M, Meadows JD, Panda S, Mellon PL (2013) Aberrant development of the suprachiasmatic nucleus and circadian rhythms in mice lacking the homeodomain protein Six6. J Biol Rhythms 28:15-25. CrossRef Medline

Colwell CS, Michel S, Itri J, Rodriguez W, Tam J, Lelievre V, Hu Z, Liu X, Waschek JA (2003) Disrupted circadian rhythms in VIP- and PHIdeficient mice. Am J Physiol Regul Integr Comp Physiol 285:R939-R949. CrossRef Medline

Cutler DJ, Haraura M, Reed HE, Shen S, Sheward WJ, Morrison CF, Marston HM, Harmar AJ, Piggins HD (2003) The mouse VPAC2 receptor confers suprachiasmatic nuclei cellular rhythmicity and responsiveness to vasoactive intestinal polypeptide in vitro. Eur J Neurosci 17:197-204. CrossRef Medline

Davis FC, Mannion J (1988) Entrainment of hamster pup circadian rhythms by prenatal melatonin injections to the mother. Am J Physiol 255:R439-R448. Medline

Diemer T, Landgraf D, Noguchi T, Pan H, Moreno JL, Welsh DK (2017) Cellular circadian oscillators in the suprachiasmatic nucleus remain coupled in the absence of connexin-36. Neuroscience 357:1-11. CrossRef Medline

Du Pré BC, Van Veen TA, Young ME, Vos MA, Doevendans PA, Van Laake LW (2014) Circadian rhythms in cell maturation. Physiology 29:72-83. CrossRef Medline

Evans JA, Gorman MR (2016) In synch but not in step: circadian clock circuits regulating plasticity in daily rhythms. Neuroscience 320:259-280. CrossRef Medline

Evans JA, Leise TL, Castanon-Cervantes O, Davidson AJ (2011) Intrinsic regulation of spatiotemporal organization within the suprachiasmatic nucleus. PloS One 6:e15869. CrossRef Medline

Harmar AJ, Marston HM, Shen S, Spratt C, West KM, Sheward WJ, Morrison CF, Dorin JR, Piggins HD, Reubi JC, Kelly JS, Maywood ES, Hastings MH (2002) The VPAC(2) receptor is essential for circadian function in the mouse suprachiasmatic nuclei. Cell 109:497-508. CrossRef Medline

Hastings MH, Brancaccio M, Maywood ES (2014) Circadian pacemaking in 
cells and circuits of the suprachiasmatic nucleus. J Neuroendocrinol 26: 2-10. CrossRef Medline

Herzog ED, Grace MS, Harrer C, Williamson J, Shinohara K, Block GD (2000) The role of Clock in the developmental expression of neuropeptides in the suprachiasmatic nucleus. J Comp Neurol 424:86-98. CrossRef Medline

Herzog ED, Kiss IZ, Mazuski C (2015) Measuring synchrony in the mammalian central circadian circuit. Methods Enzymol 552:3-22. CrossRef Medline

Honma S, Nakamura W, Shirakawa T, Honma K (2004) Diversity in the circadian periods of single neurons of the rat suprachiasmatic nucleus depends on nuclear structure and intrinsic period. Neurosci Lett 358:173176. CrossRef Medline

Houdek P, Sumová A (2014) In Vivo Initiation of Clock Gene Expression Rhythmicity in Fetal Rat Suprachiasmatic Nuclei. PLoS One 9.

Hunter JD (2007) Matplotlib: a 2D graphics environment. Comput Sci Eng 9:90-95. CrossRef

Hut RA, Beersma DG (2011) Evolution of time-keeping mechanisms: early emergence and adaptation to photoperiod. Philos Trans R Soc Lond B Biol Sci 366:2141-2154. CrossRef Medline

Inada Y, Uchida H, Umemura Y, Nakamura W, Sakai T, Koike N, Yagita K (2014) Cell and tissue-autonomous development of the circadian clock in mouse embryos. FEBS Lett 588:459-465. CrossRef Medline

Jeong B, Hong JH, Kim H, Choe HK, Kim K, Lee KJ (2016) Multi-stability of circadian phase wave within early postnatal suprachiasmatic nucleus. Sci Rep 6:21463. CrossRef Medline

Jones E, Oliphant T, Peterson P (2014) SciPy: open source scientific tools for Python. http://www.scipy.org/

Kabrita CS, Davis FC (2008) Development of the mouse suprachiasmatic nucleus: determination of time of cell origin and spatial arrangements within the nucleus. Brain Res 1195:20-27. CrossRef Medline

Kobayashi Y, Ye Z, Hensch TK (2015) Clock genes control cortical critical period timing. Neuron 86:264-275. CrossRef Medline

Kováciková Z, Sládek M, Bendová Z, Illnerová H, Sumová A (2006) Expression of clock and clock-driven genes in the rat suprachiasmatic nucleus during late fetal and early postnatal development. J Biol Rhythms 21:140148. CrossRef Medline

Kuramoto Y (2003) Chemical Oscillations, Waves, and Turbulence. New York: Springer.

Landgraf D, Achten C, Dallmann F, Oster H (2015) Embryonic development and maternal regulation of murine circadian clock function. Chronobiol Int 32:416-427. CrossRef Medline

Leise TL (2015) Wavelet-based analysis of circadian behavioral rhythms. Methods Enzymol 551:95-119. CrossRef Medline

Maywood ES, Reddy AB, Wong GK, O'Neill JS, O’Brien JA, McMahon DG, Harmar AJ, Okamura H, Hastings MH (2006) Synchronization and maintenance of timekeeping in suprachiasmatic circadian clock cells by neuropeptidergic signaling. Curr Biol 16:599-605. CrossRef Medline

Maywood ES, Chesham JE, O'Brien JA, Hastings MH (2011) A diversity of paracrine signals sustains molecular circadian cycling in suprachiasmatic nucleus circuits. Proc Natl Acad Sci U S A 108:14306-14311. CrossRef Medline

Mohawk JA, Takahashi JS (2011) Cell autonomy and synchrony of suprachiasmatic nucleus circadian oscillators. Trends Neurosci 34:349-358. CrossRef Medline

Moore RY, Bernstein ME (1989) Synaptogenesis in the rat suprachiasmatic nucleus demonstrated by electron microscopy and synapsin I immunoreactivity. J Neurosci 9:2151-2162. Medline

Ohta H, Yamazaki S, McMahon DG (2005) Constant light desynchronizes mammalian clock neurons. Nat Neurosci 8:267-269. CrossRef Medline

Ono D, Honma S, Honma K (2016) Differential roles of AVP and VIP signaling in the postnatal changes of neural networks for coherent circadian rhythms in the SCN. Sci Adv 2:e1600960. CrossRef Medline

Pérez F, Granger BE (2007) IPython: a system for interactive scientific computing. Comput Sci Eng 9:21-29. CrossRef

Pittendrigh CS (1960) Circadian rhythms and the circadian organization of living systems. Cold Spring Harb Symp Quant Biol 25:159-184. CrossRef Medline

Quintero JE, Kuhlman SJ, McMahon DG (2003) The biological clock nucleus: a multiphasic oscillator network regulated by light. J Neurosci 23: 8070-8076. Medline
Reppert SM, Schwartz WJ (1983) Maternal coordination of the fetal biological clock in utero. Science 220:969-971. CrossRef Medline

Reppert SM, Schwartz WJ (1984) The suprachiasmatic nuclei of the fetal rat: characterization of a functional circadian clock using ${ }^{14} \mathrm{C}$-labeled deoxyglucose. J Neurosci 4:1677-1682. Medline

Ruf T (1999) The Lomb-Scargle periodogram in biological rhythm research: analysis of incomplete and unequally spaced time-series. Biol Rhythm Res 30:178-201. CrossRef

Sato TK, Panda S, Miraglia LJ, Reyes TM, Rudic RD, McNamara P, Naik KA, FitzGerald GA, Kay SA, Hogenesch JB (2004) A functional genomics strategy reveals Rora as a component of the mammalian circadian clock. Neuron 43:527-537. CrossRef Medline

Schneider CA, Rasband WS, Eliceiri KW (2012) NIH Image to ImageJ: 25 years of image analysis. Nat Methods 9:671-675. CrossRef Medline

Schwartz WJ, Gross RA, Morton MT (1987) The suprachiasmatic nuclei contain a tetrodotoxin-resistant circadian pacemaker. Proc Natl Acad Sci U S A 84:1694-1698. CrossRef Medline

Seabold S, Perktold J (2010) Statsmodels: econometric and statistical modeling with python. Proceedings of the 9th Python in Science Conference.

Shibata S, Moore RY (1987) Development of neuronal activity in the rat suprachiasmatic nucleus. Brain Res 431:311-315. Medline

Shimada M, Nakamura T (1973) Time of neuron in mouse hypothalamic nuclei. Exp Neurol 41:163-173. CrossRef Medline

Shimogori T, Lee DA, Miranda-Angulo A, Yang Y, Wang H, Jiang L, Yoshida AC, Kataoka A, Mashiko H, Avetisyan M, Qi L, Qian J, Blackshaw S (2010) A genomic atlas of mouse hypothalamic development. Nat Neurosci 13:767-775. CrossRef Medline

Shimomura H, Moriya T, Sudo M, Wakamatsu H, Akiyama M, Miyake Y, Shibata S (2001) Differential daily expression of Per1 and Per2 mRNA in the suprachiasmatic nucleus of fetal and early postnatal mice. Eur J Neurosci 13:687-693. CrossRef Medline

Sládek M, Sumová A, Kováciková Z, Bendová Z, Laurinová K, Illnerová $\mathrm{H}$ (2004) Insight into molecular core clock mechanism of embryonic and early postnatal rat suprachiasmatic nucleus. Proc Natl Acad Sci U S A 101:6231-6236. CrossRef Medline

Takahashi JS (2017) Transcriptional architecture of the mammalian circadian clock. Nat Rev Genetics 18:164-179. CrossRef Medline

VanDunk C, Hunter LA, Gray PA (2011) Development, maturation, and necessity of transcription factors in the mouse suprachiasmatic nucleus. J Neurosci 31:6457-6467. CrossRef Medline

Viswanathan N, Weaver DR, Reppert SM, Davis FC (1994) Entrainment of the fetal hamster circadian pacemaker by prenatal injections of the dopamine agonist SKF 38393. J Neurosci 14:5393-5398. Medline

Wang MH, Chen N, Wang JH (2014) The coupling features of electrical synapses modulate neuronal synchrony in hypothalamic superchiasmatic nucleus. Brain Res 1550:9-17. CrossRef Medline

Weaver DR, Reppert SM (1989) Periodic feeding of SCN-lesioned pregnant rats entrains the fetal biological clock. Brain Res Dev Brain Res 46:291296. CrossRef Medline

Webb AB, Angelo N, Huettner JE, Herzog ED (2009) Intrinsic, nondeterministic circadian rhythm generation in identified mammalian neurons. Proc Natl Acad Sci U S A 106:16493-16498. CrossRef Medline

Wreschnig D, Dolatshad H, Davis FC (2014) Embryonic development of circadian oscillations in the mouse hypothalamus. J Biol Rhythms 29:299-310. CrossRef Medline

Yagita K, Horie K, Koinuma S, Nakamura W, Yamanaka I, Urasaki A, Shigeyoshi Y, Kawakami K, Shimada S, Takeda J, Uchiyama Y (2010) Development of the circadian oscillator during differentiation of mouse embryonic stem cells in vitro. Proc Natl Acad Sci U S A 107:3846-3851. CrossRef Medline

Yamaguchi S, Isejima H, Matsuo T, Okura R, Yagita K, Kobayashi M, Okamura H (2003) Synchronization of cellular clocks in the suprachiasmatic nucleus. Science 302:1408-1412. CrossRef Medline

Yan L, Okamura H (2002) Gradients in the circadian expression of Perl and Per2 genes in the rat suprachiasmatic nucleus. Eur J Neurosci 15:11531162. CrossRef Medline

Yoo SH, Yamazaki S, Lowrey PL, Shimomura K, Ko CH, Buhr ED, Siepka SM, Hong HK, Oh WJ, Yoo O, Menaker M, Takahashi JS (2004) PERIOD2: LUCIFERASE real-time reporting of circadian dynamics reveals persistent circadian oscillations in mouse peripheral tissues. Proc Natl Acad Sci U S A 101:5339-5346. CrossRef Medline 